\title{
ISAMA 2000
}

Ivars Peterson

The Second Interdisciplinary Conference of the International Society for the Arts, Mathematics, and Architecture (ISAMA) took place June 24-28, 2000 at the University at Albany-State University of New York, Albany, New York.

Why did the chicken cross the Möbius strip? To get to the same side, of course!

Kicked off with an illustrated presentation by Ivars Peterson of Science News magazine (http://www.sciencenews.org/) on the Möbius strip in culture and art, ISAMA 2000 featured a spirited intermingling of art and math, with stimulating doses of poetry, painting, sculpture, model-building, computation, puzzle, theater, dance, and much more. About 75 people, including mathematicians, computer scientists, artists, architects, teachers, and assorted others, gathered in Albany for this meeting, the latest in a series on art and mathematics that began in 1992. The indefatigable Nat Friedman (http://www.albany.edu/ -artmath/) mathematician, sculptor, and ISAMA director - organized and hosted the lively event.

A wide-ranging collection of talks filled the first three days of the meeting. During the opening session, George Hart of Northport NY (http://www.georgehart.com/) described sculpture based on propellorized polyhedra and Douglas Dunham of the University of Minnesota-Duluth (http://www.d.umn.edu/ - ddunham/)presented a novel, unified classification scheme for repeating patterns, embedding his earlier work on hyperbolic tessellations in a broader framework. That afternoon, art professor and printmaker Thom O'Connor (see his homepage, http://www.albany.edu/finearts/thom_oconnor.html, and Photography in Focus, http://www.albany.edu/feature99/oconnor) of the University at Albany displayed his subtly textured studies of geometry and light, inspired by northern European skyscapes and other settings. Award-winning poet Stephanie Strickland of New York City eloquently enumerated the intertwining of mathematical ideas and verse along multithreaded pathways (see TrueNorth.html, http://www.eastgate.com/catalog/TrueNorth.html and an online collection of poems, http://califia.hispeed.com/SI/stone1a.htm ). Robert J. Krawczyk of the Illinois Institute of Technology in Chicago (http://home.netcom.com/-bitart/mathtrek.htm\#3 ) explored the algorithmic art of spirolateral reversals (and handed out samples of notecards based on his designs). Eva Knoll of Montreal, Quebec, and Simon Morgan of Rice University in Houston played with deltahedra - polyhedra in which all faces are equilateral triangles of the same size. Finally, artist Douglas Peden of Essex, N.Y., illustrated how wavy grids can form a basis for intriguing abstract paintings.

Sunday morning started off with artist Larry Kagan of the Rensselaer Polytechnic Institute in Troy, N.Y., describing his fascination with scrap steel and shadows and his development of new sculptural forms by looking for visual rules among seemingly random assemblages. Kagan was followed by sculptor Robert Longhurst of Chestertown NY (http://www.cs. berkeley. edu/ sequin/SCULPTS/LONGHURST/) talking about "poetry in wood", as visualized in elegant wood carvings of forms that could readily pass for minimal surfaces. Sculptor and computer artist Thomas Sakoulas of SUNY-Onenonta (http://home.stny.rr.com/sakoulas/) described his interest in the purity of geometric sculpture and the attraction of opposing elements or ideas in art. In the afternoon, Edward Mayer of the University at Albany

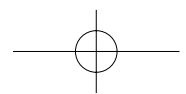


(http://www.albany.edu/finearts/edward_mayer.html) led a grand visual tour of his ventures into architectural sculpture, based on stacking wood laths and other materials into various, impermanent structures. Sculptor Charles Ginnever (http://www.base24.com/gallery/ GINNEVER/gin2.htm) showed a series of intriguingly angular, cantilevered steel sculptures - optical illusions writ large. Allen Linder of College Park MD displayed a remarkable assemblage of hand-carved stone sculptures based on spheres and divisions of space. Susan Happersett of Jersey City NJ talked about her mathematical meditations on Fibonacci numbers - in the form of delicately rendered and ingeniously packaged drawings in which pen strokes evoke number and density. Hana M. Bizek of Westmont IL (http://cube.misto. czl_MAIL_/) displayed colorful, three-dimensional structures built from Rubik's cubes. Elizabeth Whiteley of Washington DC talked about designs for woodwork and paintings based on the square roots of 2,3, and 5 - harmonic decompositions of space related to the Platonic solids (her work is available on two webpages, Elizabeth Whiteley on Koan ArtWow, http://www.koanart.com/beth.html, and Elizabeth Whiteley in the Women Artist Archive, http://libweb.sonoma.edu/special/waa/whiteley/).

The final day of talks started off with a strongly mathematical flavor. Mathematician George Francis of the University of Illinois at Urbana-Champaign (http://www.math.uiuc.edu/ -gfrancis/) brought his attentive audience into the realm of mathematical visualization metarealistic rendering of four-dimensional and non-Euclidean phenomena. John Sullivan (http://www.math.uiuc.edu/ -jms/), also from Urbana, looked at artful ways of turning spheres inside out. Colin Adams of Williams College in Williamstown MA (http://www.williams. edu/Mathematics/cadams/) and author of The Knot Book: An Elementary Introduction to the Mathematical Theory of Knots, got entangled in knots. Frank Morgan of Williams (http://www. williams.edu/Mathematics/fmorgan/) presented the proof of the double-bubble conjecture. Monday afternoon. Eleni Mylonas of New York City (http://www.elenimylonas.com/) displayed her stunning visual explorations of Penrose tilings and quasiperiodic arrays. Printmaker and sculptor Benigna Chilla of Berkshire Community College in Pittsfield MA and modern dance choreographer Ellen Sinopoli (http://www.sinopolidances.com/default.htm) recounted a remarkable collaboration that integrated geometry and dance - bringing together physical movement and optical form. Zelma Looseke (http://www.libertynet.org/pmacraft/lgzl.html) of Montpelier VT described her amazing woven-willow constructions, which look like quaintly rustic renderings of exotic topological forms.

Two more days were devoted to hands-on teacher workshops. George Hart orchestrated a series of Zometool constructions of various polyhedral forms (see the Zometool homepage, http://www.zometool.com/, and George Hart's Zome Geometry page, http://www.georgehart. com/zomebook/zomebook.html); Nat Friedman delved into hyperseeing and hypersculptures; John Sullivan conducted a workshop on computer-generated sculpture; Doug Dunham supervised the construction of hyperbolic tessellations. Friedman also introduced the crafting of fractal stone prints, knot sculptures, and soap-film minimal surfaces.

A number of participants displayed their artworks and wares. Magnus Wenninger (http:// www.employees.csbsju.edu/mwenninger/) patiently constructed polyhedral models. Doug Peden showed examples of his grid paintings; and John Sharp (http://www.mathsyear2000. org/resources/slice/) exhibited "sliceform" models of polyhedra. 
The entire program proved to be a feast of mathematical and artistic surprises. Participants found it wonderfully stimulating and exhilarating. That's precisely what Friedman had in mind when he organized the first art and mathematics meeting in 1992 and later started ISAMA, which is devoted to furthering interdisciplinary education relating art, mathematics, and architecture.

Information about the International Society for the Arts, Mathematics, and Architecture (ISAMA) and its meetings can be found on the ISAMA webpage (http://www.isama.org/). A list of speakers and a display of photographs from ISAMA 2000 are available on the ISAMA 2000 conference webpage (http://www.isama.org/isama/conf/isama00).

The following online MathTrek articles by Ivars Peterson describe presentations made at ISAMA 2000:

Turtle Tracks (http://www.sciencenews.org/20000722/mathtrek.asp)

Art of the Grid (http://www.sciencenews.org/20000812/mathtrek.asp)

Online MathTrek articles on related topics:

Möbius at Fermilab (http://www.sciencenews.org/20000902/mathtrek.asp)

Scrambled Grids (http://www.sciencenews.org/20000826/mathtrek.asp)

Möbius and His Band (http://www.sciencenews.org/20000708/mathtrek.asp)

Sliding Pi (http://www.sciencenews.org/20000603/mathtrek.asp)

A Minimal Winter's Tale (http://www.sciencenews.org/20000205/mathtrek.asp)

First published in the NNJ online October 2000

\section{The reporter}

Ivars Peterson is the mathematics/computer writer and online editor at Science News magazine in Washington DC. He is the author of The Mathematical Tourist, Islands of Truth, Newton's Clock, Fatal Defect, and The Jungles of Randomness. He also writes for the children's magazine Muse and is working on a book about math and art. 